\title{
Fisiopatologia da psoríase e seus aspectos imunológicos: uma revisão sistemática
}

\author{
Physiopathology of psoriasis and its immunological aspects: a systematic review \\ Fisiopatología de la psoriasis y sus aspectos inmunológicos: una revisión sistemática
}

\section{Resumo}

A complexidade da psoríase, a escassa correlação clínica com demais aspectos influentes e a dificuldade dos tratamentos relacionados a ela, dificulta a melhora dos quadros clínicos de diversos indivíduos que sofrem com a doença. Por esse motivo, é de extrema importância buscar compreender melhor seus mecanismos e fatores externos envolventes na patologia, para um melhor auxílio no tratamento. O objetivo da pesquisa é conhecer os mecanismos imunológicos da inflamação, bem como compreender de que maneira os demais fatores podem influenciar na causa ou agravamento da psoríase no organismo do indivíduo. Para o seu desenvolvimento foram realizadas buscas eletrônicas nas bases de dados, como Google Scholar, Pubmed, Scielo e Science Direct. Em síntese, pode-se observar a atuação de diversas células do sistema imune na inflamação, como linfócitos $\mathrm{T}$ e citocinas sinalizadoras, que são importantes marcadores para a doença, a interleucina-6, além da proteína C reativa que é uma proteína de fase aguda, estão elevadas no processo fisiopatológico da doença. Por outro lado, os estímulos externos e estresse, demonstram uma correlação clínica considerável com o desenvolvimento do quadro patológico. Sendo assim, o controle das interleucinas em especial a IL6, torna-se uma ferramenta útil no monitoramento e melhora da fisiopatologia da doença.

Palavras-chave: Psoríase; Reação autoimune; Fatores genéticos; Inflamação; Mecanismos imunológicos; Fisiopatologia; Citocinas inflamatórias; Marcadores bioquímicos; Fatores emocionais.

\begin{abstract}
The complexity of psoriasis, the poor clinical correlation with other influential aspects and the difficulty of treatments related to it, make it difficult to improve the clinical conditions of several individuals who suffer from the disease. For this reason, it is extremely important to seek to better understand its mechanisms and external factors surrounding the pathology, for a better treatment aid. The objective of the research is to understand the immunological mechanisms of inflammation, as well as to understand how the other factors can influence the cause or worsening of psoriasis in the individual's body. For its development, electronic searches were carried out in the databases, such as Google Scholar, Pubmed, Scielo and Science Direct. In summary, it is possible to observe the action of several cells of the immune system in inflammation, such as $\mathrm{T}$ lymphocytes and signaling cytokines, which are important markers for the disease, interleukin-6, in addition to the reactive protein $\mathrm{C}$ which is an acute phase protein, are elevated in the pathophysiological process of the disease. On the other hand, external stimuli and stress, demonstrate a considerable clinical correlation with the development of the pathological condition. Thus, the control of interleukins, especially IL-6, becomes a useful tool in monitoring and improving the pathophysiology of the disease.

Keywords: Psoriasis; Autoimmune reaction; Genetic factors; Inflammation; Immunological mechanisms; Pathophysiology; Inflammatory cytokines; Biochemical markers; Emotional factors.

\section{Resumen}

La complejidad de la psoriasis, la escasa correlación clínica con otros aspectos influyentes y la dificultad de los tratamientos relacionados con ella, dificultan la mejora de las condiciones clínicas de varios individuos que padecen la enfermedad. Por ello, es de suma importancia buscar conocer mejor sus mecanismos y factores externos implicados en la patología, para una mejor ayuda al tratamiento. El objetivo de la investigación es comprender los mecanismos inmunológicos de la inflamación, así como comprender cómo los otros factores pueden influir en la causa o el empeoramiento de la psoriasis en el organismo del individuo. Para su desarrollo se realizaron búsquedas electrónicas en las bases de datos, como Google Scholar, Pubmed, Scielo y Science Direct. En resumen, es posible observar el
\end{abstract}


desempeño de varias células del sistema inmunológico en la inflamación, como los linfocitos $\mathrm{T}$ y las citocinas de señalización, que son marcadores importantes de la enfermedad, la interleucina- 6 , además de la proteína $C$ reactiva, que es una proteína de fase aguda., se encuentran elevadas en el proceso fisiopatológico de la enfermedad. Por otro lado, los estímulos externos y el estrés, demuestran una correlación clínica considerable con el desarrollo de la condición patológica. Así, el control de interleucinas, especialmente IL-6, se convierte en una herramienta útil en el seguimiento y mejora de la fisiopatología de la enfermedad.

Palabras clave: Psoriasis; Reacción autoinmune; Factores genéticos; Inflamación; Mecanismos inmunológicos; Fisiopatología; Citocinas inflamatorias; Marcadores bioquímicos; Factores emocionales.

\section{Introdução}

A Psoríase é uma doença crônica diretamente relacionada com a imunidade do indivíduo. Compreender a fisiopatologia e os mecanismos imunológicos envolvidos nas alterações patológicas é de suma importância para auxiliar no tratamento da doença.

É uma doença autoimune que possui influência de diversos fatores, como emocional, ambiental e genético, e atinge cerca de 1 a 3\% da população entre homens e mulheres, na faixa etária de 10 a 45 anos (El-Dairi \& House, 2019). Suas lesões afetam diversas áreas do corpo, sendo os joelhos, mãos, couro cabeludo, unhas e tronco algumas delas (Machado et al., 2019). A patologia é uma hiperplasia epidérmica e uma ativação imune inapropriada na pele e articulações. A doença é caracterizada pela predominância de linfócitos $\mathrm{T}$ e macrófagos em que há interação entre os linfócitos $\mathrm{T}$ ativados, células apresentadoras de antígeno (APC) e células residentes, como por exemplo os queratinócitos. A comunicação entre elas ocorre através de citocinas, sendo o fator de necrose tumoral alfa (TNF- $\alpha$ ) uma das mais importantes (Carneiro, 2007).

A psoríase assume vários tipos, sendo a mais comum a psoríase em placas ou vulgar. Esta, forma placas avermelhadas que descamam e coçam, podendo ocorrer sangramento em casos mais graves. Além desse tipo, ainda ocorrem a ungueal, invertida, gutata, pustulosa, eritrodérmica, a que acomete o couro cabeludo, e a artropática, que atinge as articulações (SBD, 2017).

A falta de informação faz com que a doença seja confundida com outros tipos de doenças da pele como alergias, do cabelo como caspas, das unhas como micoses, e o aumento do constrangimento que as lesões causam, levando os pacientes a desenvolverem doenças psicológicas e sociais. O conhecimento da fisiopatologia da doença auxilia a diagnosticar e tratar minimizando suas complicações sistêmicas e melhorando a qualidade de vida dos pacientes, além de possibilitar traçar terapias complementares com a utilização de produtos naturais.

\section{Metodologia}

O estudo trata-se de uma pesquisa bibliográfica sistemática, constituída de livros e artigos científicos (Pereira et al. 2018). Foi efetuada uma revisão de literatura sobre o tema através de revistas acadêmicas científicas e artigos em bancos de dados, tais como Scielo, Science Direct, Teses da USP e Google Scholar. Diversos tópicos que correlacionam a psoríase com o sistema imunológico e outros fatores foram abordados, avaliando as alterações características do sistema imunológico em relação à patologia. O estudo incluiu a busca de palavras chaves como "psoríase", "reação auto imune", "fatores genéticos", "inflamação", "mecanismos imunológicos", "fisiopatologia", "citocinas inflamatórias", "marcadores bioquímicos", "fatores emocionais" (Tabela 1). Os critérios de inclusão foram: artigos publicados entre 1993 e 2020, originais, em língua portuguesa, inglesa e espanhola, que obedeciam às palavras chaves descritas. Foram excluídos editoriais e opiniões. Será desempenhada apenas a revisão teórica, o estudo não realizará experimentos nem pesquisas de forma direta, somente dados publicados até o momento para interesse da comunidade científica e populacional. 


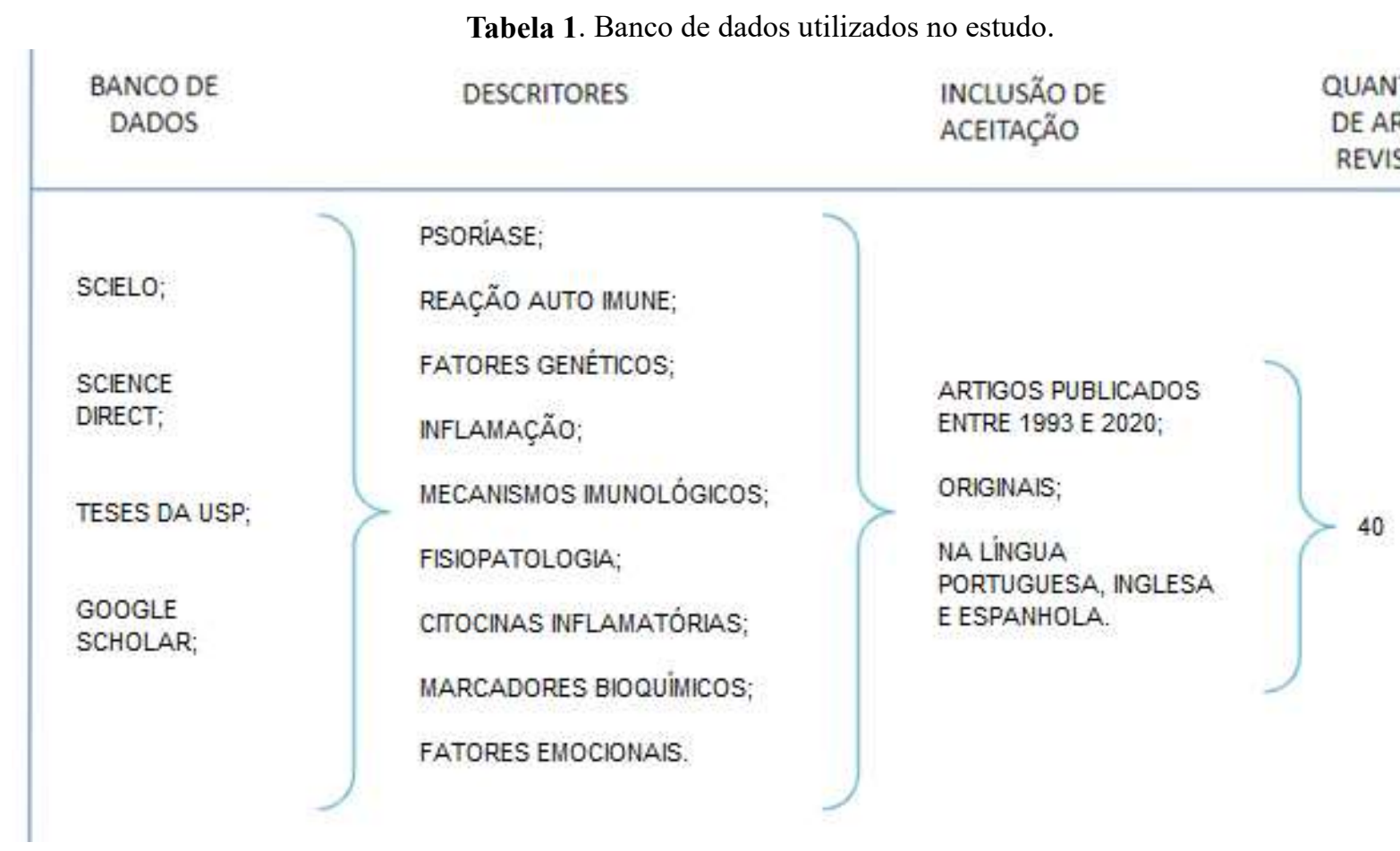

Fonte: Autores.

\section{Resultados e Discussão}

Foram levantados 60 artigos científicos sendo 50 na língua portuguesa, 8 na língua inglesa e 2 na língua espanhola. Para este estudo foram utilizados 40 artigos científicos, sendo excluídos 20 que não se enquadraram nos critérios estabelecidos. Do total de artigos levantados, 49,99\% abordaram os conceitos imunológicos como ponto de partida para as alterações morfológicas na psoríase, $16,66 \%$ dos artigos publicados descrevem elevação dos marcadores bioquímicos de inflamação tais como: PCR. Por outro lado, alguns autores têm relatado uma relação direta entre o estresse e o aparecimento da psoríase. A psoríase, palavra que vem do grego Psora, é uma doença muito antiga com relatos desde os tempos Bíblicos até o século XVIII, também era considerada contagiosa e confundida com a hanseníase (Rezende, 2014).

Hipócrates (460-375 a.C) classificou as lesões com aspectos parecidos com os da psoríase, erupções escamosas denominando-as de lepo (descamar). Galeno (133-200 d.C.) foi o primeiro a utilizar a palavra psoríase. Em 1809 o dermatologista britânico Robert Willan estudou a psoríase e propôs o termo Psoriasis e descreveu as variedades clínicas da doença, mas somente em 1841 a psoríase foi separada da hanseníase pelo médico dermatologista Austríaco Ferdinand Von Hebra (Romiti et al, 2009).

\section{Achados clínicos da psoríase}

A psoríase pode acometer qualquer área da pele, sendo mais comum no cotovelo, joelho, unha e couro cabeludo. Achados clínicos da psoríase na infância têm alta incidência familiar e um terço dos adultos adquire a doença antes dos 16 anos de idade, quanto mais precoce o surgimento da doença mais grave é a evolução do quadro (Romiti et al., 2009).

A forma mais comum na infância é caracterizada pelo surgimento de placas eritematosas bem delimitadas envolvendo a genitália e as regiões glútea e peri umbilical. A psoríase em placas é a forma mais comum, são placas elevadas, avermelhadas e cobertas por escamas prateadas. Já a psoríase gutata são pequenas lesões avermelhadas em forma de gota que aparecem no tronco, braços e pernas. Psoríase invertida são lesões avermelhadas com pouca ou nenhuma descamação na área de dobras da pele como virilhas, axila, glúteo, abaixo do seio e ao redor dos órgãos genitais, piorando com a fricção e a umidade do suor. A 
psoríase ungueal afeta as unhas dos pés e das mãos, causando crescimento anormal e a descoloração, em casos mais graves podendo cair.

Psoríase do couro cabeludo são áreas avermelhadas com escamas branco-prateadas que se estendem além da linha do cabelo, aparecendo ao redor das orelhas, testa e na nuca. Psoríase pustulosa são lesões avermelhadas, dolorosas e com pústulas. Psoríase eritrodérmica é a forma mais grave e rara da doença, podendo cobrir todo corpo, deixando o paciente exposto a infecções graves, a inflamação da pele faz com que a pele perca a capacidade de agir como uma barreira protetora contra patógenos. Artrite psoriásica nas mãos, aparece em articulações de pessoas com psoríase, ocorrendo a deformação das articulações (Figura 1).

Figura 1. Achados clínicos da psoríase.

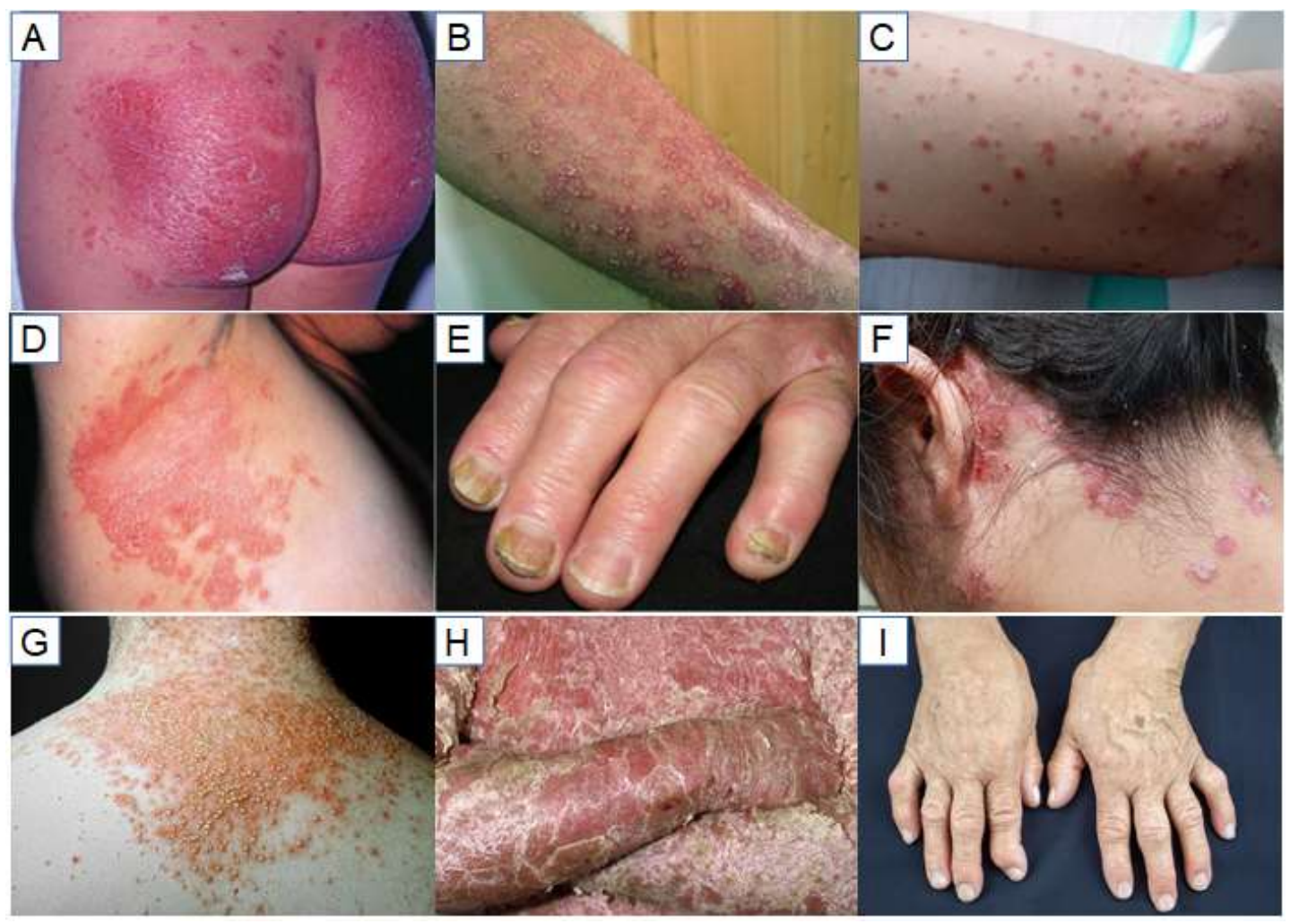

Legenda: A) Psoríase na região do glúteo pelo uso de fraldas; B) Psoríase em placas; C) Psoríase gutata; D) Psoríase invertida; E) Psoríase ungueal; F) Psoríase no couro cabeludo; G) Psoríase pustulosa; H) Psoríase eritrodérmica; I) Artrite Psoriásica nas mãos.

Fonte: Pinheiros, P. (2021). https://www.mdsaude.com/dermatologia/fotos-de-psoriase/

Fonte: Romiti et al, 2009; Medicsupply 2016; Dr. Pedro Pinheiro, MD. Saúde 2008-2020; Dermatologia Aripuanã Coberio 2020; Sociedade Brasileira de Dermatologia 2017; Dr. Pedro Pinheiro, MD. Saúde 2008-2020; Tua Saúde 2007 - 2020.

\section{Diagnóstico da psoríase}

O diagnóstico de um indivíduo com psoríase é simples, em que se baseia no seu histórico familiar e clínica, visto que a psoríase possui aparência dérmica característica, com eritema vermelho claro, escamas espessas, bem como inflamação e prurido. Além dessas características, a psoríase ainda apresenta uniformidade, sinal de vela, sinal de Auspitz e zona clara perilesional (halo de Woronoff) (Takahashi, 2009).

O diagnóstico laboratorial não tem grande finalidade, somente como auxílio no diagnóstico diferencial (SBD, 2006). A curetagem metódica de Brocq é o método de diagnóstico utilizado na psoríase em que, evidencia-se o sinal de vela ao revelar a estratificação das escamas, e o sinal de Auspitz, que através da raspagem do método, surgem pequenos pontos sangrantes. Em lesões menos típicas, é necessário a realização de biópsia para confirmação (Takahashi, 2009). 


\section{Fisiopatologia da psoríase}

A psoríase é uma patologia que possui alterações histológicas ocasionando lesões cutâneas. Pesquisas imunológicas têm possibilitado definir a doença segundo mecanismos que o próprio sistema imunológico possui, sendo dessa forma, classificada como inflamação (Lima, 2011). É uma doença autoimune que possui dois processos: Pró-inflamatório e proliferação de células na epiderme, sendo os queratinócitos os principais tipos celulares presentes na lesão (Krueger, 2005). Há também uma correlação da psoríase com aspectos psicossociais, como por exemplo, entre vários outros eventos psicológicos, o estresse.

A psoríase cutânea apresenta diversas formas, que vão desde psoríase em placas até a eritrodérmica, passando pela pustulosa, gutata, ungueal, invertida e a forma patológica que acomete o couro cabeludo. A psoríase artropática é a doença que, além da inflamação dérmica e descamação, também atinge as articulações e pode estar associada a qualquer outra forma clínica.

\section{Mecanismo imunopatológico e inflamatório da psoríase}

As alterações observadas na psoríase são ocasionadas por células plasmocitóides, mieloides e células dendríticas maduras, que são ativadas na epiderme e na derme. Essas células são responsáveis pela produção das subclasses de células Th1 (T helper) e Tc1 (T citotóxicas), que secretam os indutores da produção de HLA-DR (human leukocyte antigen localizado no lócus gênico DR) nos queratinócitos, os mediadores IFN-y (Interferon gama), reativando o processo inflamatório (Lima, 2011). Existe uma complexidade na imunopatogênese da psoríase, visto que essa patologia envolve tanto sistema imunológico inato, quanto o sistema imunológico adquirido. As células participantes do sistema imune inato, quando ativadas, produzem quimiocinas e citocinas que atuam sobre o sistema imune adquirido e vice-versa (Sanchez, 2010).

Para que se inicie o processo inflamatório, primeiramente é necessário que as células do sistema imune inato sejam ativadas, sendo as células dendríticas (CD) e queratinócitos. Uma vez que os queratinócitos são ativados, os mesmos liberam citocinas - interleucinas e TNF- $\alpha$ (fator de necrose tumoral alfa) - e proteínas de choque térmico (Sanchez, 2010). Um componente presente nas células da epiderme será reconhecido pelo sistema imune, esse componente é a proteína SLC9A3R1, responsável pelo transporte antiporte de sódio e prótons, presente nos queratinócitos epiteliais. Ao ser reconhecida, vai haver modificações genéticas nos linfócitos T que reconhecerão a proteína SLC9A3R1 - apresentada pelas CD - podendo haver modificações genéticas na própria proteína (Krueger, 2005).

As CD fagocitarão algumas células da epiderme e vão processar alguns antígenos, externalizando a proteína processada via MHC I (complexo de histocompatibilidade humana de classe I). Ao reconhecer a proteína, os linfócitos T sofrem uma etapa de diferenciação, além de receber sinalização de outras células do sistema imune para promover sua diferenciação. O LT CD4 + se diferencia em LTh17 e ela secreta as interleucinas (IL) 17 e 22 (Krueger, 2005).

As IL-17 e IL-22 são as responsáveis por promover respostas nos queratinócitos presentes na derme do indivíduo. Essa resposta faz com que os queratinócitos ativem sua proliferação celular de forma contínua, visto que a apresentação antigênica será contínua e os LTh17 irão continuamente secretar as IL. Além disso, outras células irão proliferar, como os macrófagos ativados que vão secretar IL-20, IL-19, IL-24 (Krueger, 2005). Portanto, para que haja a ativação das células T, é necessário que ocorra uma "sinapse imunológica" entre as mesmas e as proteínas da membrana da célula apresentadora de antígeno (Figura 2) (Sanchez, 2010). 
Figura 2. Mecanismo imunopatológico e inflamatório da psoríase.

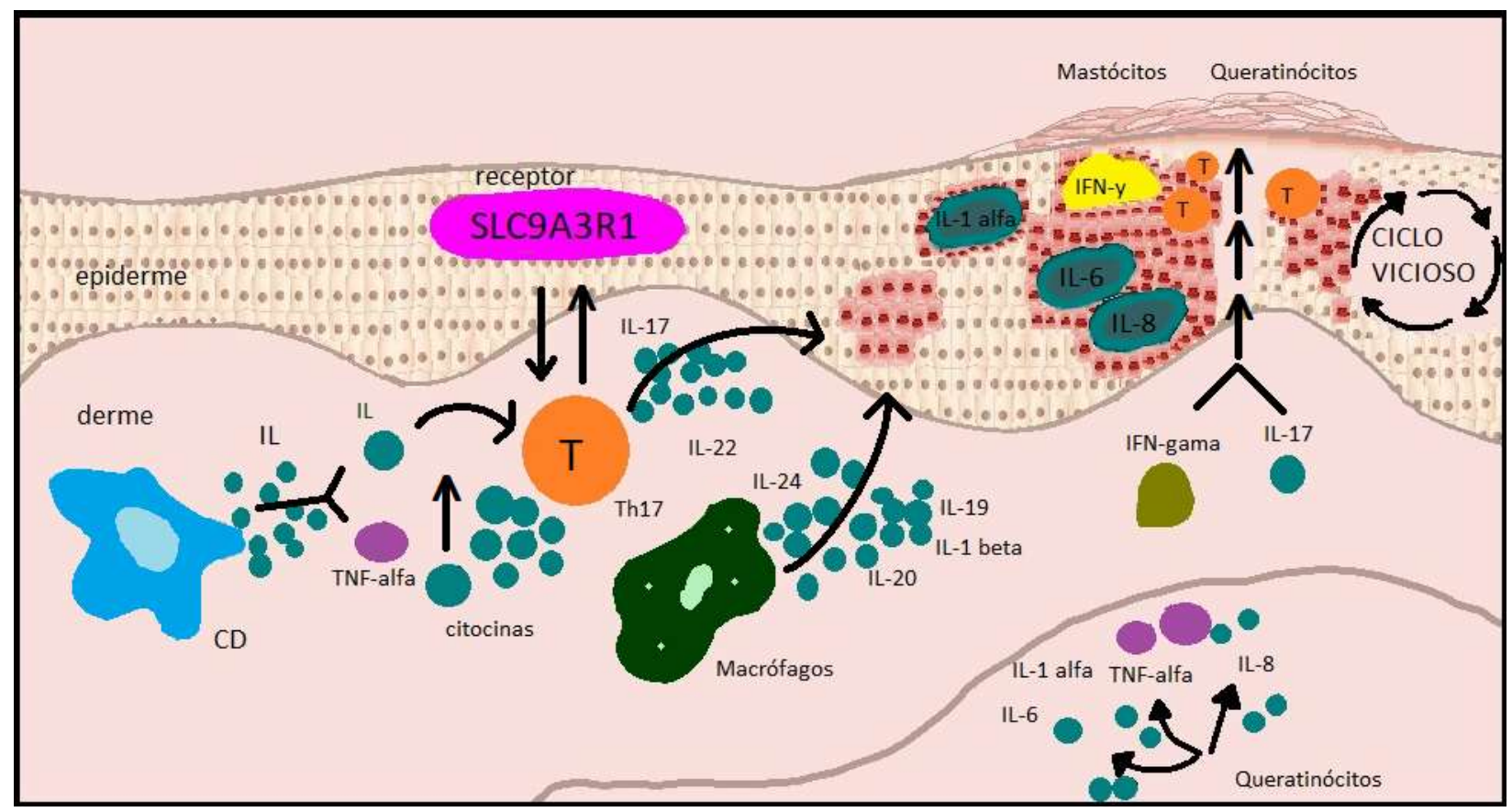

Fonte: Autores.

A cascata da inflamação psoriásica envolve diversos acontecimentos. A primeira citocina participante é a IL-12, que desencadeia os linfócitos TCD4 e CD8. Após a diferenciação para Th1 e Tc1, estes sintetizam IL-2, TNF- $\alpha$, IFN-y, fator estimulador de colônias de granulócitos e leucócitos (GM-CSF), e fator de crescimento epidérmico (EGF). O TNF- $\alpha$ é responsável por aumentar a liberação de citocinas, sendo estas essenciais durante a cascata da inflamação. Na maturação, as células T produzem novas proteínas de superfície, cujo a mais importante é o antígeno associado ao linfócito cutâneo (CLA). As moléculas ICAM-1 (Intracelular Adhesion Molecule-1) e VCAM-1 (Vascular Adhesion Molecule-1) somado ao CLA, exercem a maturação e quimiotaxia linfocitária, assim como de neutrófilos e macrófagos para a lesão, por ativação do endotélio vascular (Lima, 2011).

Existem outros fatores significativos para a formação da lesão psoriásica, sendo estes o IFN-y, promovendo a hiperproliferação dos queratinócitos por inibição da apoptose, além de aumentar a expressão de ICAM-1 nas células do endotélio, o que facilita a circulação linfocitária; e a IL-17, que interagindo com o IFN-y aumentam a síntese de citocinas pró-inflamatórias pelos queratinócitos, elevando o influxo de células T na pele, contribuindo assim para a manutenção da placa inflamatória (Lima, 2011).

Os queratinócitos também liberam citocinas inflamatórias, que são o TNF- $\alpha$, a IL-6 (responsável por estimular a proliferação dos queratinócitos), IL-8 que além de estimular a proliferação dos queratinócitos, também aumentam a quimiotaxia de neutrófilos, promovendo a ruptura dos desmossomos de queratinócitos e formação de microabscesso de Munro (neutrófilos na paraqueratose), e fator de transformação de crescimento, responsável pela angiogênese e hiperpermeabilidade vascular (Lima, 2011).

A produção de IL-1 origina principalmente de monócitos e macrófagos, produzindo a interleucina-1 $\beta$ (IL-1 $\beta$ ), enquanto os queratinócitos, interleucina-1 $\alpha$ (IL-1 $\alpha$ ) (Varellal, Forte, 2001). A IL-1 $\beta$ 'é uma citocina pró-inflamatória potente importante nas respostas de defesa (Castejon, Brough, 2011) que além de ser produzida pelos macrófagos e monócitos, também são expressas por células Natural Killer (NK) e neutrófilos, todas do sistema imune inato (Giraldo, et al., 2008). Nas lesões de psoríase, há 
predomínio de linfócitos T helper, com padrão Th1, caracterizado pelo aumento de IL-1 $\beta$, bem como IFN-y e TNF- $\alpha$ (Torres, Filipe, 2014).

A hiperproliferação observada na psoríase se deve às injúrias ocasionadas pelas citocinas estimuladoras IL-1 $\alpha$, IL-6, IFN-y e presença de células T entre os queratinócitos. Há também a participação da IL-8 e consequentemente o recrutamento de neutrófilos, o que desencadeia ainda mais injúria entre os queratinócitos (Lima, 2011). Essas citocinas sinalizam os queratinócitos para que haja a proliferação de forma contínua. Conforme os queratinócitos proliferam, eles se sobrepõem um ao outro, formando a placa celular na pele do indivíduo, uma das principais características superficiais da psoríase. Torna-se um ciclo vicioso, pois conforme as citocinas são produzidas - são elas pró-inflamatórias e sinalizadoras para respostas mutagênicas, ou seja, proliferação celular - haverá um aumento da população celular e juntamente uma resposta pró-inflamatória, ocasionando as lesões teciduais (Krueger, 2005).

O prurido é bastante característico da lesão, estando presente em mais de $70 \%$ dos pacientes (Carneiro, 2007). No prurido, os mastócitos (Mcs) exercem um papel importante, visto que possui capacidade de produzir, armazenar e liberar diferentes substâncias biologicamente ativas, o que justifica sua participação nas reações imunes, considerando também que há relatos de seu aumento numérico nas lesões de psoríase (Nakamura et al., 2003).

\section{Marcadores bioquímicos e inflamatórios}

Em 1989, TNF- $\alpha$ e IL-6 foram identificados como biomarcadores da psoríase, porém há outros constituintes da inflamação. Os níveis séricos elevados de leptina e resistina se correlacionam com uma maior gravidade da doença, em que a resistina está associada ao aumento de outras citocinas pró-inflamatórias (Duarte, 2015).

A osteopontina (OPN) é uma glicoproteína produzida pelas células do sistema imune, responsável por potencializar respostas imunes de padrão Th1 e inibir respostas de padrão Th2. Em indivíduos com psoríase, sugere-se uma elevação da OPN. A IL-18, a IL-22 e o fator transformador de crescimento beta 1 plasmático (TGF- $\beta 1$ ) também se encontram elevados (Duarte, 2015).

A IL-18 assim como a IL-6 são de suma importância no processo da psoríase, pois a IL-18 aumenta a resposta inflamatória, enquanto a IL-6 estimula os hepatócitos para produzir proteínas da fase aguda da inflamação (proteína C reativa, amilase A sérica), assim como está presente em reações alérgicas (Varellal, Forte, 2001). Já a IL-22 é uma citocina próinflamatória que atua na ativação dos neutrófilos e macrófagos, e na produção de GM-CSF (Torres, Filipe, 2014).

A PCR é uma das principais proteínas de fase aguda do processo inflamatório da psoríase, sendo expressada pelas IL-6 através dos hepatócitos (Oliboni, et al., 2016). É caracterizada como proteína de fase aguda positiva, pois sua concentração sérica é elevada no processo de desencadeamento da doença (Aguiar, Christo, 2015). Segundo Fernandes (2010), quando comparada a indivíduos saudáveis, observa-se um aumento significativo da PCR em indivíduos portadores da psoríase.

Além da PCR, outra proteína de fase aguda, a amilase A sérica (SAA) é encontrada em elevações significativas em portadores da doença. Também caracterizada como proteína de fase aguda positiva, na inflamação da pele a expressão de SAA é aumentada, e segundo Sirin, et al., (2020), ela é um marcador ainda mais específico do que a PCR. A PCR e a SAA são os indicadores mais sensíveis à inflamação e encontraremos elevados em pacientes portadores da psoríase.

\section{Genética associada a fatores ambientais}

Sabe-se que, além de fatores imunológicos e emocionais, há uma diversidade de causas que podem favorecer o aparecimento da lesão psoriática, entre elas encontram-se causas genéticas, visto que essa doença pode ser hereditária. Um indivíduo pode ter um componente genético e nascer com predisposição para ter psoríase - relata um estudo - em uma amostra de pessoas, metade dos indivíduos relataram ter diagnóstico de psoríase na família (Silva, Silva, 2007). 
O alelo HLA, que traduzido significa Antígeno Leucocitário Humano, possui grande variabilidade com relação à etnia, tipos e manifestações clínicas da doença. Há uma forte associação do alelo HLA-Cw*0602 em grupos étnicos distintos, porém, apenas $10 \%$ dos indivíduos que possuem esse alelo, desenvolvem a doença (Alves, 2006).

A doença é associada com algumas classes de HLAs, como HLA-B13, HLA-Bw 57, HLA-Cw6 e HLA-DR7, sendo o mais prevalente o HLA-Cw6, tendo incidência entre 45 à 86\% em estudos com Caucasianos (Rodrigues, Teixiera, 2009). A presença desse antígeno significa um risco cerca de 9 a 15 vezes maior do portador ter a doença (Ponzio, 1992).

Uma anormalidade à nível de MHC I, no alelo HLA-Cw6 resulta no seu reconhecimento como antígeno estranho pelo MHC de classe I restrito as células T CD8, fator que desencadeia a inflamação crônica considerada autoimune (Rodrigues, Teixiera, 2009).

"História familiar positiva para psoríase [...] apareceu em 14\%" (Carneiro, 2007). "Estudos recentes revelam loci de susceptibilidade denominados Psors, localizados nos cromossomos 6p, 17q, 4q e 1q" (Romiti, 2009). No entanto, somente o sistema HLA não é suficiente para justificar o aparecimento da psoríase, deve-se considerar outros fatores participantes de sua patogênese.

\section{Fatores psicossociais}

O estresse emocional pode colaborar para a piora do quadro clínico. A relação à aparência física da pessoa com psoríase é vista como um fator estressante, a rejeição que os limita colocando-os em uma condição inferior, o sofrimento em uma sociedade que estabelece padrões de beleza e de adequação, podendo também influenciar na capacidade de autoaceitação e levar o indivíduo a depressão (Silva et al., 2007). Em pacientes com quadros clínicos mais graves e disseminadas pelo corpo, ocasionam maior limitação e desadaptação social pela desfiguração na aparência, favorecendo a discriminação da pessoa portadora da doença (Mingorance, 1999).

Algumas doenças dermatológicas têm relação com aspectos emocionais da pessoa, a pele é classificada como um órgão de choque que sofre essas oscilações emocionais manifestando na pele a psoríase (Steiner, Perfeito, 2003). O constrangimento das lesões e a piora estão relacionados com o desencadeamento do estresse emocional (Silva et al., 2007). A psoríase no seu estado agudo, tendo a alta visibilidade das lesões causa um alto impacto psicossocial negativo na vida das pessoas que são acometidas por essa doença, os impossibilitando de realizar atividades rotineiras evitando o receio da exposição do corpo, o julgamento das pessoas ao pensar que as lesões são contagiosas, levando ao constrangimento e irritação e desenvolvendo mecanismos de isolamento social (Silva et al., 2007).

A procura de um especialista para o diagnóstico e tratamento medicamentoso das lesões é recomendável. Com o adoecimento resultante do constrangimento das exposições das lesões e o isolamento social, exige a reorganização das atividades rotineiras e readaptação social, necessitando de uma abordagem multiprofissional que atenda às necessidades do paciente com psoríase a enfrentar melhor o quadro clínico e a ter a autoaceitação da doença (Silva et al., 2007).

O estresse é estímulo que provoca excitação emocional e altera a homeostasia, ocasiona o aumento da secreção de adrenalina produzindo manifestações sistêmicas, distúrbios fisiológicos e psicológicos. A percepção de cada indivíduo em relação a divergências do meio interno e externo, relacionado a sua capacidade de resposta frente aos problemas emocionais (Margins et al., 2003).

O estresse emocional é um potente desencadeador e agravador da reincidência da psoríase. Sendo também definida como uma psicodermatose, o estresse não desencadeia só a psoríase como outras dermatoses (lúpus eritematoso), considerando então a relação entre a pele e o estado emocional (Melo, et al., 2019). 
Segundo Mingorance, et al., (1999), a psoríase é vista como uma maneira não verbal do corpo em expressar esses sentimentos. A incapacidade do portador da psoríase não está relacionada à dificuldade do indivíduo expressar as suas emoções, mas sim pela incapacidade de suportar o excesso delas pela experiência negativa psicossocial vivida (Melo, et al., 2019).

$\mathrm{Na}$ Psoríase as células de defesa que resultam do processo inflamatório proliferam pela epiderme, os linfócitos $\mathrm{T}$ age no desencadeamento e na manutenção da inflamação, sendo responsável pela imunopatologia da psoríase pela liberação das citocinas pró inflamatórias (Aguiar, Christo, 2015).

A pele é constituída pela epiderme e pela derme, derivada embriologicamente do ectoderma e do mesoderma, a epiderme se desenvolve do ectoderma onde o neuroectoderma forma o sistema nervoso, dando assim origem ainda no desenvolvimento embrionário a dois órgãos importantes do corpo, a pele e o sistema nervoso, comprovando assim a ligação dos fatores psicoemocionais com a doença dermatológica (Martins et al., 2017).

A resposta fisiológica ao estresse envolve o eixo hipotálamo-hipófise-adrenal (HHA), o sistema nervoso autônomo e o sistema imunológico, quando o sistema nervoso autônomo é ativado por um fator estressante, ocorre a liberação de adrenalina e noradrenalina pela medula supra renal através do nervo vago, e logo após ocorre a ativação do eixo HHA que libera o hormônio liberador de corticotrofina (CRH) pelo hipotálamo, liberando em seguida pela hipófise a corticotrofina (ACTH) que sinaliza para medula supra-renal aumentar a produção e a liberação de cortisol na corrente sanguínea (Harvima, 2012).

O estresse crônico suprime o eixo HHA elevando os níveis de corticotrofina (CRH) e glicocorticoides (GC), a pele é um importante órgão neuroendócrino as células dendríticas da pele são ativadas pelo estresse levando a liberação de neuro mediadores e catecolaminas pelas terminações nervosas contribuindo para a piora da doença, o hormônio liberador de corticotrofina $(\mathrm{CRH})$ é sintetizado na pele causando a ativação dos mastócitos e o aumento da permeabilidade vascular contribuindo na inflamação cutânea e retardando o processo de cicatrização das feridas, a inibindo a síntese de lipídeos epidérmicos levando ao aumento da proliferação dos queratinócitos e o aumento da substância P que facilitam os processos inflamatórios e a ativação de linfócitos Th17 e Th1 (Harvima, 2012).

A IL-18 é uma citocina moduladora de respostas imunes, seu receptor é expresso no sistema nervoso central participando de processos neuro inflamatórios, neurodegenerativos e também influência a homeostase e o comportamento (Alboni, et al., 2010).

Segundo Sekiyama, et al., (2005), testes de respostas ao estresse na imobilização em camundongos foram realizados, para a análise da IL-18, as proteínas precursoras de IL-18 no córtex adrenal são induzidas por estresse via ACTH e pela via de ativação de caspase 1 mediada por superóxido, convertendo em pró-IL-18 na forma madura e liberada no plasma. Os inibidores de caspase 1 impedem o acúmulo de IL-18 induzido pelo estresse, e também bloqueiam a expressão de IL-6 induzida pelo estresse, observou-se que IL-6 não foi induzida em camundongos estressados deficientes em IL-18 e que a indução de IL-6 por estresse é dependente de IL-18, sendo ela influenciadora de processos patológicos e físiológicos do estresse.

O aumento da produção de IL-6 está associado ao distúrbio da homeostase, reações imuno inflamatórias, estresse físico e psicológico causando o aumento da produção de IL-6, essa afirmação foi obtida através da exposição de ratos a choques elétricos, estímulo aversivo e contenção física, o teste mostrou o aumento dos níveis plasmáticos de IL-6 e a semelhança com o aumento da corticosterona plasmática, a liberação de IL-6 no plasma pode estar sob a regulação de respostas neurais e endócrinas ao estresse (Zhou D, et al., 1993).

A liberação da enzima alfa amilase foi relatada em um projeto em adultos saudáveis que foram expostos a condições de estresse social e de repouso, a alfa amilase salivar, o cortisol salivar e a frequência cardíaca foram medidos repetidamente antes, durante e depois das condições de estresse e repouso. Foram observados aumentos significativos nos níveis da alfa amilase antes e depois do estresse, sendo assim um marcador promissor e confiável do estresse psicossocial (Nater M, et al., 2005). Rohleder, 
et al (2004) cita que a alfa amilase salivar é aumentada pelo estresse psicossocial agudo e se relaciona com o aumento da norepinefrina plasmática. Portanto, esses biomarcadores salivares podem ser úteis para avaliar o estresse mental.

Quadro 1. Marcadores imunológicos da psoríase e do estresse.

\begin{tabular}{|c|c|}
\hline Marcadores da psoríase & Marcadores do estresse \\
\hline IL -18 & IL -18 \\
\hline alfa amilase salivar & alfa amilase salivar \\
\hline IL -6 & $\mathrm{IL}-6$ \\
\hline TNF $-\alpha$ & TNF $-\alpha$ \\
\hline PCR & PCR \\
\hline
\end{tabular}

Fonte: Autores.

\section{Conclusão}

Em síntese, a presente revisão bibliográfica demonstra que a inflamação com elevação das interleucinas 6,18 , TNF- $\alpha$ e a PCR, são marcadores que estarão presentes tanto na psoríase quanto no estresse. Desta forma, torna-se de suma importância controlar a elevação dos referidos marcadores para controlar a patologia e auxiliar em seus tratamentos. Desde hereditariedade até os fatores emocionais, a dermatose tem uma importante associação, visto que eles ocasionam e/ou agravam o estado do quadro que afetam a vida do indivíduo.

Dentre as sugestões para trabalhos futuros, pode-se levantar um maior aprofundamento em estudos clínicos para ampliar conhecimentos a respeito de fatores externos e internos interferentes, como hereditariedade e estresse emocional, a fim de melhorar a compreensão da visão clínica e avançar nos tratamentos.

\section{Agradecimentos}

A Universidade José do Rosário Vellano e cursos de Farmácia e Biomedicina.

\section{Referências}

Alboni, S., Cervia, D., Sugama, S., \& Conti, B. (2010). Interleukin 18 in the CNS. Journal of Neuroinflammation, 7, 1-12. https://doi.org/10.1186/1742-2094$7-9$

Alves, C., Vieira, N., Meyer, I., Alves, C. O., Toralles, M. B. P., \& Oliveira, M. de F. S. P. (2006). Antígenos de histocompatibilidade humanos e dermatologia: da pesquisa para a prática clínica. Anais Brasileiros de Dermatologia, 81(1), 65-73. https://doi.org/10.1590/s0365-05962006000100009

Aparecida, L., Aguiar, R., \& Christo, D. De. (2017). Cadernos da Escola de Saúde Psoríase Relacionada A Marcadores Autoimunes: Um Estudo De Caso Psoriasis Related To Autoimmune Markers : A Case Study A hereditariedade desempenha um importante papel na psoríase , porém, a doença só é. 39-51.

Carneiro, S. (2007). Psoríase: mecanismos de doença e implicações terapêuticas. 213.

Dal Pont, M. F., et al (2017). a Psoriase Sob OO Olhar Da Psicologia Corporal. 1-10. http://www.centroreichiano.com.br/artigos_livres.htm.

de Sousa Silva, K., \& da Silva, E. A. T. (2007). Psoríase e sua relação com aspectos psicológicos, stress e eventos da vida. = Psoriasis and its relation with psychological aspects, stress, and life events. Estudos de Psicologia, 24(2), 257-266. http://search.ebscohost.com/login.aspx?direct=true\&db=psyh\&AN=200709609-012\&site=ehost-live\%0Ahttp://kenia@laal.com.br

Denise, M., \& Takahashi, F. (2009). Manisfestações Clínicas, Diagnóstico, Diagnóstico diferencial. 23-29.

Duarte, G. (2015). Avaliação de marcadores clínicos e biológicos associados com a Psoríase Vulgar. 114 . https://repositorio.ufba.br/ri/bitstream/ri/24389/1/Tese_ICS_Gleison Vieira Duarte.pdf 
El-Dairi, M., \& House, R. J. (2019). Optic nerve hypoplasia. In Handbook of Pediatric Retinal OCT and the Eye-Brain Connection (pp. 285-287). https://doi.org/10.1016/B978-0-323-60984-5.00062-7

Faria, J. R. C. de, Aarão, A. R., Jimenez, L. M. Z., Silva, O. H., \& Avelleira, J. C. R. (2010). Importância da variação do PASI realizado por diversos observadores. Anais Brasileiros de Dermatologia, 85(5), 625-629. https://doi.org/10.1590/s0365-05962010000500005

Fernandes, B., Ferreira, P. L., \& Figueiredo, A. (2010). Qualidade De Vida Nos Doentes Com Psoríase. Criação Da Versão Portuguesa Do Psoriasis Disability Index. Journal of the Portuguese Society of Dermatology and Venereology. https://doi.org/10.29021/spdv.70.1.38

González-Parra, S., \& Daudén, E. (2019). Psoriasis and Depression: The Role of Inflammation. Actas Dermo-Sifiliográficas (English Edition), 110(1), 12-19. https://doi.org/10.1016/j.adengl.2018.05.035

Harvima IT, Nilsson G. Stress, the neuroendocrine system and mast cells: current understanding of their role in psoriasis. Expert Rev Clin Immunol. 2012 Mar;8(3):235-41. 10.1586/eci.12.1.

Kluger, N., \& Assouly, P. (2011). Pseudopelade de Brocq. Annales de Dermatologie et de Venereologie, 138(5), 430-433. https://doi.org/10.1016/j.annder.2011.01.025

Krueger, J. G., \& Bowcock, A. (2005). Psoriasis pathophysiology: Current concepts of pathogenesis. Annals of the Rheumatic Diseases, 64(SUPPL. 2), 30-36. https://doi.org/10.1136/ard.2004.031120

Lima, E. de A., \& Lima, M. de A. (2011). Imunopatogênese da psoríase: revisando conceitos. Anais Brasileiros de Dermatologia, 86(6), 1151-1158. https://doi.org/10.1590/s0365-05962011000600014

Lopez-Castejon, G., \& Brough, D. (2011). Understanding the mechanism of IL-1 $\beta$ secretion. Cytokine and Growth Factor Reviews, 22(4), 189-195. https://doi.org/10.1016/j.cytogfr.2011.10.001

Machado, E. R., Oliveira, L. B., Chaves, P. L. G., Gomes, L. O. R. G., \& Lins, J. P. (2019). Psoríase: uma revisão sistemática da literatura. Rev Inic Cient e Ext, 2,52 .

Melo, M. S. B. de, Rocha, N. F. L., Magalhães, S. S., \& Sousa, L. L. (2019). Influência de fatores emocionais nas doenças crônicas de pele: O estresse como gatilho para o desenvolvimento, reincidência ou agravamento da psoríase / Influence of emotional factors on chronic skin diseases: Stress as a trigger for development, recurren. ID on Line Revista De Psicologia, 13(46), 584-608. https://doi.org/10.14295/idonline.v13i46.1914

Mingorance, R. C., Loureiro, S. R., Okino, L., \& Foss, N. T. (2010). Pacientes Com Psoríase: Adaptação Psicossocial E Características De Personalidade. Medicina (Ribeirao Preto. Online), 3/4. https://doi.org/10.11606/issn.2176-7262.v34i3/4p315-324

Nater, U. M., Rohleder, N., Gaab, J., Berger, S., Jud, A., Kirschbaum, C., \& Ehlert, U. (2005). Human salivary alpha-amylase reactivity in a psychosocial stress paradigm. International Journal of Psychophysiology, 55(3), 333-342. https://doi.org/10.1016/j.ijpsycho.2004.09.009

Oliboni, L., Casarin, J. N., \& Chielle, E. O. (2016). Correlação entre a concentração sérica de interleucina-6 (IL-6) e biomarcadores de resistência insulínica em adultos jovens obesos. Clinical \& Biomedical Research, 36(3), 148-155. https://doi.org/10.4322/2357-9730.65335

Pereira, A., Shitsuka, D., Parreira, F., \& Shitsuka, R. (2018). Metodologia da Pesquisa Científica. In Metodologia da Pesquisa Científica. https://repositorio.ufsm.br/bitstream/handle/1/15824/Lic_Computacao_Metodologia-Pesquisa-Cientifica.pdf?sequence=1.

Pinheiros, P. (2021). https://www.mdsaude.com/dermatologia/fotos-de-psoriase/

Regina, M., Patrícia, P., Annelise, C., \& Ricardo, S. (2003). Relação entre estressores, estresse e ansiedade. Rev Psicatric. RS, 65-74.

Rezende, J. M. de. (2014). Psoríase. Psoríaco, Psórico, Psoriático, Psoriásico. Revista de Patologia Tropical, 43(1), 105-107. https://doi.org/10.5216/rpt.v43i1.29379

Rohleder, N., Nater, U. M., Wolf, J. M., Ehlert, U., \& Kirschbaum, C. (2004). Psychosocial stress-induced activation of salivary alpha-amylase: An indicator of sympathetic activity? Annals of the New York Academy of Sciences, 1032, 258-263. https://doi.org/10.1196/annals.1314.033

Romiti, R., Maragno, L., Arnone, M., \& Takahashi, M. D. F. (2009). Psoríase na infância e na adolescência. Anais Brasileiros de Dermatologia, 84(1), 09-20. https://doi.org/10.1590/s0365-05962009000100002

Sanchez, A. P. G. (2010). Immunopathogenesis of psoriasis. Anais Brasileiros de Dermatologia, 85(5), 747-749. https://doi.org/10.1590/s036505962010000500028

Sekiyama, A., Ueda, H., Kashiwamura, S. I., Nishida, K., Kawai, K., Teshima-Kondo, S., Rokutan, K., \& Okamura, H. (2005). IL-18; a cytokine translates a stress into medical science. Journal of Medical Investigation, 52(SUPPL.), 236-239. https://doi.org/10.2152/jmi.52.236

Sirin, M. C., Korkmaz, S., Erturan, I., Filiz, B., Aridogan, B. C., \& Cetin, E. S. (2020). Avaliação da razão dos monócitos/colesterol HDL e outros marcadores inflamatórios em pacientes com psoríase. 95(5).

Sousa, A. L. de. (2007). Avaliação de estresse, morbidade psiquiátrica e marcadores inflamatórios em indivíduos de baixo status socioeconômico. Journal of Chemical Information and Modeling.

Torres, T., \& Bettencourt, N. (2014). Psoriasis: The visible killer. Revista Portuguesa de Cardiologia (English Edition), 33(2), 95-99. https://doi.org/10.1016/j.repce.2013.06.033

Torres, T., \& Filipe, P. (2014). Interleukin-17 as a therapeutic target in psoriasis. Acta Medica Portuguesa, 27(2), 252-258. https://doi.org/10.20344/amp.4777 
Research, Society and Development, v. 10, n. 11, e256101119346, 2021

(CC BY 4.0) | ISSN 2525-3409 | DOI: http://dx.doi.org/10.33448/rsd-v10i11.19346

Varella, P. P. V, \& Forte, W. C. N. (2001). Citocinas: revisão. Revista Brasileira de Alergia e Imunopatologia, 24, 146-154.

Zhou, D., Kusnecov, A. W., Shurin, M. R., DePaoli, M., \& Rabin, B. S. (1993). A exposição a estressores físicos e psicológicos eleva a interleucina 6 plasmática: relação com a ativação do eixo hipotálamo-hipófise-adrenal. Endocrinology, 133(6), 2523-2530. 